\title{
Probabilistic Simulation of Combined Thermo-Mechanical Cyclic Fatigue in Composites
}

\author{
C.C. Chamis ${ }^{1}$ \\ NASA Glenn Research Center, Cleveland, Ohio 44135
}

\begin{abstract}
A methodology to compute probabilistically-combined thermo-mechanical fatigue life of polymer matrix laminated composites has been developed and is demonstrated. Matrix degradation effects caused by long-term environmental exposure and mechanical/thermal cyclic loads are accounted for in the simulation process. A unified time-temperature-stressdependent multifactor-interaction relationship developed at NASA Glenn Research Center has been used to model the degradation/aging of material properties due to cyclic loads. The fast probability-integration method is used to compute probabilistic distribution of response. Sensitivities of fatigue life reliability to uncertainties in the primitive random variables (e.g., constituent properties, fiber volume ratio, void volume ratio, ply thickness, etc.) computed and their significance in the reliability-based design for maximum life is discussed. The effect of variation in the thermal cyclic loads on the fatigue reliability for a $(0 / \pm 45 / 90)_{s}$ graphite/epoxy laminate with a ply thickness of $0.127 \mathrm{~mm}$, with respect to impending failure modes has been studied. The results show that, at low mechanical-cyclic loads and low thermal-cyclic amplitudes, fatigue life for $\mathbf{0 . 9 9 9}$ reliability is most sensitive to matrix compressive strength, matrix modulus, thermal expansion coefficient, and ply thickness. Whereas at high mechanical-cyclic loads and high thermal-cyclic amplitudes, fatigue life at 0.999 reliability is more sensitive to the shear strength of matrix, longitudinal fiber modulus, matrix modulus, and ply thickness.
\end{abstract}

\section{Nomenclature}

$\begin{array}{ll}\mathrm{E}_{\mathrm{f} 11,22,23} & =\text { fiber normal modulus } \\ \mathrm{E}_{\mathrm{m}} & =\text { matrix normal modulus } \\ \mathrm{G}_{\mathrm{f} 12,13,23} & =\text { fiber shear modulus } \\ \mathrm{k}_{\mathrm{f}} & =\text { actual fiber volume ratio } \\ \mathrm{k}_{\mathrm{v}} & =\text { apparent void volume ratio } \\ 1_{, \mathrm{m}, \mathrm{n}, \mathrm{p}, \mathrm{q}} & =\text { exponents for multifactor interaction equation } \\ \mathrm{M}_{\mathrm{P}} & =\text { material property } \\ \mathrm{M}_{\mathrm{PO}} & =\text { reference material property } \\ \mathrm{N} & =\text { number of effects causing material degradation } \\ \mathrm{N}_{\mathrm{m}} & =\text { number of mechanical cycles } \\ \mathrm{N}_{\mathrm{mf}} & =\text { final number of mechanical cycles } \\ \mathrm{N}_{\mathrm{T}} & =\text { number of thermal cycles } \\ \mathrm{N}_{\mathrm{Tf}} & =\text { final number of thermal cycles } \\ \mathrm{p} & =\text { coefficient of variation } \\ \mathrm{r} & =\text { applied stress to laminate ratio } \\ \mathrm{S} & =\text { final strength } \\ \mathrm{S}_{\mathrm{f}} & =\text { fiber strength } \\ \mathrm{S}_{\mathrm{fC}} & =\text { fiber compressive strength } \\ \mathrm{S}_{\mathrm{fT}} & =\text { fiber tensile strength } \\ \mathrm{S}_{\mathrm{mC}} & =\text { matrix compressive strength } \\ \mathrm{S}_{\mathrm{mS}} & =\text { matrix shear strength } \\ \mathrm{S}_{\mathrm{mT}} & =\text { matrix tensile strength } \\ \mathrm{T} & =\text { temperature } \\ \mathrm{T}_{\mathrm{gd}} & =\text { dry glass transition temperature } \\ \mathrm{T}_{\mathrm{gw}} & =\text { wet glass transition temperature } \\ \mathrm{T}_{\mathrm{o}} & =\text { initial temperature } \\ \mathrm{t} & =\text { current time } \\ & \end{array}$

\footnotetext{
${ }^{1}$ Senior Aerospace Scientist, Research and Technology Directorate, 21000 Brookpark Road, and AIAA Fellow.
} 
$\mathrm{t}_{\mathrm{f}} \quad=$ final time

$\mathrm{t}_{1} \quad=$ ply thickness

$\mathrm{V}=$ primitive variable for material or load (e.g., temperature, stress, mechanical cycles, etc.)

$\mathrm{V}_{\mathrm{F}} \quad=$ value of primitive variable at final condition

$\mathrm{V}_{\mathrm{O}} \quad=$ value of primitive variable at reference condition

$\alpha_{\mathrm{m}} \quad=$ matrix thermal expansion coefficient

$\mu \quad=$ mean value

$v_{\mathrm{f} 12,13,23}=$ fiber Poisson's ratio

$v_{\mathrm{m} 12,13,23}=$ matrix Poisson's ratio

$\sigma \quad=$ stress

$\sigma_{\mathrm{M}} \quad=$ mechanical cyclic stress amplitude

$\sigma_{\mathrm{T}} \quad=$ thermal cyclic stress amplitude

\section{Introduction}

$\mathrm{T}$ HE aeronautics industry is in continuing pursuit of lightweight structural concepts for both airframe primary structures and engine structural components. One of the prime issues for these structural components is assured long-term behavior with a specified reliability. These objectives are being addressed through the use of accelerated testing strategies as well as computational simulation methodologies for predicting long-term durability of structural components. The present article addresses issues pertaining to probabilistic fatigue life of polymer matrix composites under a combined thermal- and mechanical-cyclic loading through the use of some typical examples.

The complexity of predicting composite behavior is compounded by the presence of multiple scales that must be considered in the simulation. These are the micro-level scale where fiber, matrix, and interface participate, the macro-level where individual plies take part, and the laminate level where the ply configuration becomes important. Additionally, the fabrication process can induce variations, there are inherent uncertainties in the constituent properties, and the cyclic variations in an aggressive loading environment all contribute to the ever increasing complexity in the computational simulation. Successful inclusion of the lighter high-temperature composites for future aircraft hinges largely upon the ability to predict and assure their long-term behavior. Current practices depend largely on a building block approach of conducting long-term testing of materials in the form of coupons up through components. However, this is time consuming and expensive to conduct a large number of long-term tests to capture the effects of all the design variables and loads. Furthermore, accounting for the previously discussed uncertainties in the experiments is a monetarily unfeasible proposition. Therefore in view of these facts, realization of the full potential of lightweight composites is more likely to be achieved with the real innovative computational approaches capable of handling these aspects in an integrated manner together, with some accelerated and strategically-chosen experiments to minimize the testing costs. Also such computational procedures provide $a$ priori insight to identify critical experiments to be performed as well as reduce the number of tests to be conducted to an optimum number.

Traditional computational approaches are deterministic in nature; they do not account for uncertainties associated with composite structures and materials. The focus of ongoing research at the NASA Glenn Research Center has been to develop advanced integrated computational methods and related computer codes to perform a complete probabilistic assessment of composite structures. These methods account for uncertainties in all the constituent properties, fabrication process variables, and loads to predict probabilistic micro, ply, laminate, and structural responses. These methods have already been implemented in the Integrated Probabilistic Assessment of Composite Structures (IPACS) ${ }^{1}$ computer code.

The objective of this article is to describe a computational simulation methodology to predict the fatigue life reliability and probabilistic long-term behavior in polymer matrix composites. Also, the implementation of the methodology in the ICAN computer code ${ }^{2}$ has been described. A unified time, stress, and load-dependent multifactor-interaction equation (MFIE) model ${ }^{3}$ developed at the NASA Glenn Research Center has been used to simulate the long term behavior of polymer matrix composites.

To illustrate the application of the methodology, a typical composite system consisting of graphite fibers in epoxy matrix is chosen. The methodology can be applied to other types of polymer matrix composites as well. The layup of the composite system is chosen as $(0 / \pm 45 / 90)_{s}$. The cumulative probability distribution functions (CDF's) for combined thermal mechanical fatigue is computed. The fatigue life cycles are computed for different applied stress to laminate strength ratios, $r$. The laminate strength is evaluated based on first ply failure criteria (hereinafter referred to as laminate strength). First ply failure criteria assumes that the laminate has failed when any stress component in a ply exceeds its respective allowable limit. By using these CDF's a fatigue life cycle curve for a reliability of 0.999 is obtained in order to demonstrate how this methodology can be used to aid the design process. Also, the sensitivity of fatigue life reliability to the primitive random variables are computed for a reliability of 0.999. It is noted that the computer codes are continuously updated, but the concepts remain the same as described in the initial references. 


\section{Computational Simulation}

Simulation of uncertainties in the primitive random variables throughout the load history requires fundamental governing field equations in time variable. The probabilistic simulation process in this article uses time dependent MFIE model, micromechanics theory, and the fast probability integration (FPI) theory. ${ }^{4}$ Uncertainties in the primitive variables related to physical process fabrication, constituent properties, and ply geometry are included in the simulation. Micromechanics theory available in the ICAN computer code has been used together with the MFIE to include the degradation of constituent properties resulting from aggressive load effects for the simulation of long term effects. A generic form of the previous model is given by

$$
\frac{\mathrm{M}_{\mathrm{P}}}{\mathrm{M}_{\mathrm{PO}}}=\prod_{\mathrm{i}=1}^{\mathrm{N}}\left[\frac{\mathrm{V}_{\mathrm{F}}-\mathrm{V}}{\mathrm{V}_{\mathrm{F}}-\mathrm{V}_{\mathrm{O}}}\right]_{\mathrm{i}}^{\mathrm{a}}
$$

The terms in parenthesis represent a physical effect that causes the degradation of material property. The exponent accounts for the amount of degradation due to a particular effect. More details on this model are given later in this article. The following sections describe the developed/modified computer codes and procedures used in the computational simulation of probabilistic long-term behavior in polymer matrix composites subjected to combined thermo-mechanical fatigue.

\section{A. Integrated Composite Analyzer (ICAN)}

The ICAN code computationally simulates the material behavior of polymer matrix composites from fiber/matrix constituents to the laminate scale including fabrication effects (Fig. 1). ICAN uses composite micromechanics and laminate analysis based on linear elastic theory to compute constituent, ply, and laminate level properties required for the global structural analysis (left side of Fig. 1). ICAN also decomposes the global structural response to laminate, ply, and constituent response levels (stress and strains) which helps the user to evaluate failure (right side of Fig. 1). Details of the ICAN computer code are given in Reference 2. ICAN also performs the failure analysis based on different failure criteria such as first-ply failure criteria, fiber break criteria, modified distortion energy criterion, and Hoffman's criteria.

The ICAN computer code was modified to implement the time-dependent MFIE and perform sensitivity evaluation for primitive random variables. The time variable in the MFIE is divided into a smaller number of time steps to simulate long-term effects. At every time step the degradation magnitude of the matrix properties, which are used in micro-mechanics and laminate analysis, is evaluated. Response variable sensitivity to the random variables at every time step are also performed to compute the respective scatter in response variables. Also, at every time step a failure analysis based on first-ply failure and fiber break criteria is performed to determine whether the laminate can take any further load. Failure analysis determines the possible failure modes and maximum load capacity in the respective failure mode. The analysis stops when the laminate is incapable of carrying any more

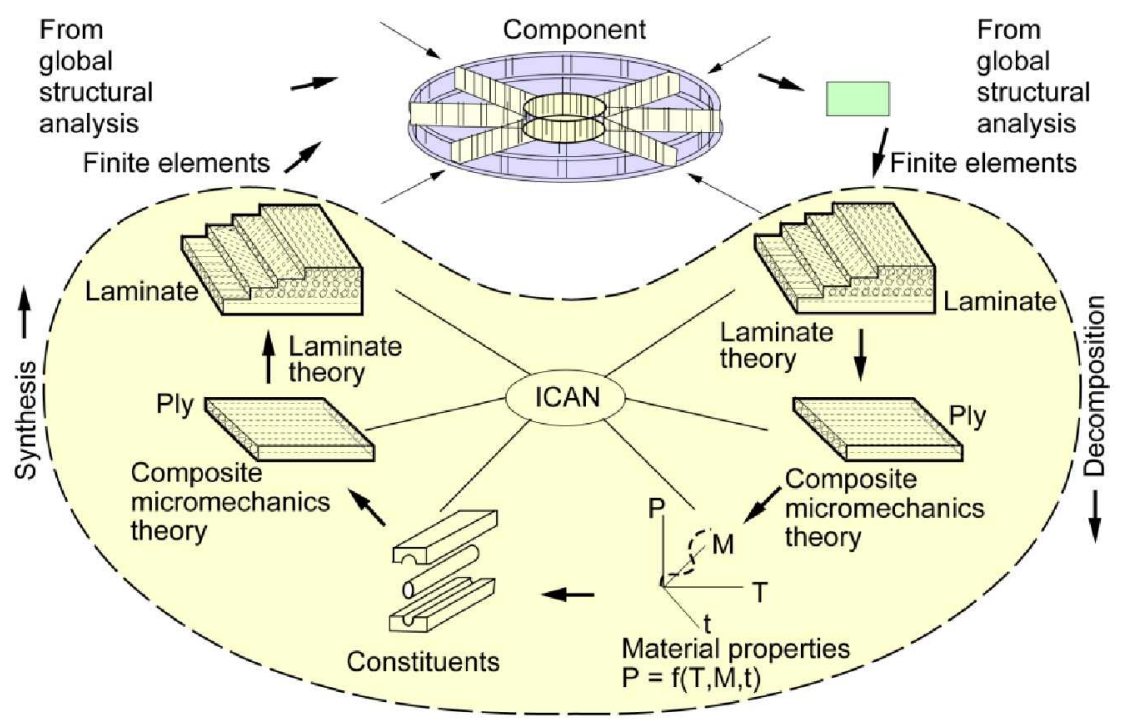

Figure 1. Schematic of ICAN computer code. 
load. In addition, a data base is created to store results required to perform probabilistic life analysis and develop reliability-based life assessment of polymer matrix composites. Thus, the current version of ICAN is capable of performing probabilistic time variable analysis to incorporate material degradation due to combined thermal and mechanical cyclic loads.

\section{B. Time Dependent Multi-Factor Interaction Equation (MFIE) Model}

It is known that predicting the behavior of composite materials is a complex task. Accounting for all the physical effects and how they affect the material properties in the time domain is even more complex. Over the years, research in developing a unified law describing the material behavior driven by primitive variables has been an ongoing activity at NASA Glenn Research Center. The result of this research is the development of a unified MFIE model. ${ }^{3}$ Concepts used in Reference 3 have been expanded to include the time-dependent degradation effect on material behavior because of environmental, fabrication, and load effects. ${ }^{5}$ The modified form of the equation including time effect in expanded form is

$$
\frac{M_{P}}{M_{P O}}=\left(\frac{T_{g w}-T}{T_{g d}-T_{o}}\right)^{1}\left(1-\frac{\sigma}{S_{f}}\right)^{m}\left(1-\frac{\sigma_{T}}{S_{f} t_{f}}\right)^{n}\left(1-\frac{\sigma_{M} N_{m}}{S_{f} N_{m f}}\right)^{p}\left(1-\frac{\sigma_{T} N_{T}}{S_{f} N_{T f}}\right)^{q}\left(1-\frac{t}{t_{f}}\right)^{r}
$$

Each term in parenthesis accounts for a specific physical effect. Any number of effects can be included in one single equation as seen by the nature of the equation. The exponents are determined from the available experimental data or estimated from the anticipated material behavior due to a particular primitive variable. Each primitive variable and the exponent in the previous equation can be random with a statistical distribution. The insufficiency of a set of experimental data can be taken into account by means of uncertainties in the exponent.

An important part of the previous model is the fact that only one equation can include all the effects with any nonlinearity in the material behavior and follow the physics of behavior. It can describe all of the interacting effects of different variables (thermal, metallurgical, mechanical, chemical, and load). Since the variables used are at a primitive level, it simulates the in situ degradation in material properties caused by applied cyclic and environmental effects.

\section{Probabilistic Simulation}

An advanced first-order second-moment fast probability integration (FPI) technique ${ }^{4}$ is used to compute cumulative-probability distribution function of the fatigue life. Results of the random variable perturbations are used to compute the CDF of responses. The FPI technique is very efficient compared to the Monte Carlo simulation technique. FPI does not generate random samples; however, it does use a numerical integration technique to compute the joint probability density functions and probability of failures. It transforms the physical random variable space system into unit normal space to perform probability integration easily and more accurately. On the other hand, the Monte Carlo method generates a large number of random samples to compute the CDF of response. Hence, FPI is computationally more economical than Monte Carlo. The sensitivity of responses is also computed by FPI. Sensitivity information helps improve the design and quality.

\section{Simulation Cases, Results, and Discussion}

Probabilistic simulation of long-term behavior under mechanical cyclic loads only was demonstrated in Reference 5. In this report the methodology has been extended to simulate probabilistic long-term behavior and fatigue reliability under combined thermo-mechanical cyclic loads. Probabilistic behavior of a graphite/epoxy laminate as an illustrative example is studied. The deterministic long-term behavioral aspects for polymer matrix composites are discussed in Reference 6. A $(0 / \pm 45 / 90)_{\text {s }}$ laminate made of graphite fibers and epoxy matrix is subjected to uniaxial mechanical tensile and thermal cyclic load as shown in Fig. 2. The load shown in Fig. 2 is sinusoidal. However, any cyclic load shape such as triangular, square, and so forth can be used by accounting for this through the exponent value in MFIE. Each ply has a thickness of $0.127 \mathrm{~mm}$. Typical mean values, scatter, and probability distribution of all the fiber, matrix properties, and fabrication variables are taken as those given in Table $1{ }^{2}$ Normal distribution for the primitive variables has been assumed in the present study. However, any other type of distribution for these variables can be used in the described methodology. Initially, the laminate was subjected to a mean static load, and failure analysis was performed to evaluate static laminate strength. It was found to be $1184.0 \mathrm{~kg}$ per unit $\mathrm{cm}$ width based on the first ply failure criteria. Several simulation cases, with different combinations of mechanical and thermal load magnitudes, given in Table 2 were analyzed, and the CDF's and sensitivity evaluations were performed. The mechanical load is applied as a ratio, $r$, defined as applied mechanical stress over static laminate strength. These load cases are divided into three categories. The first category includes 


\section{Composite: \\ Graphite/epoxy \\ Laminate configuration: \\ $(0 / \pm 45 / 90)_{s}$}

Ply thickness, $0.127 \mathrm{~mm}$

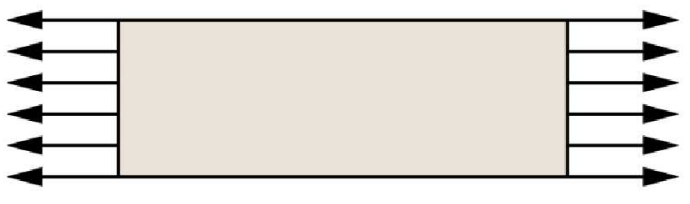

Figure 2. Description of thermo-mechanical cyclic load.
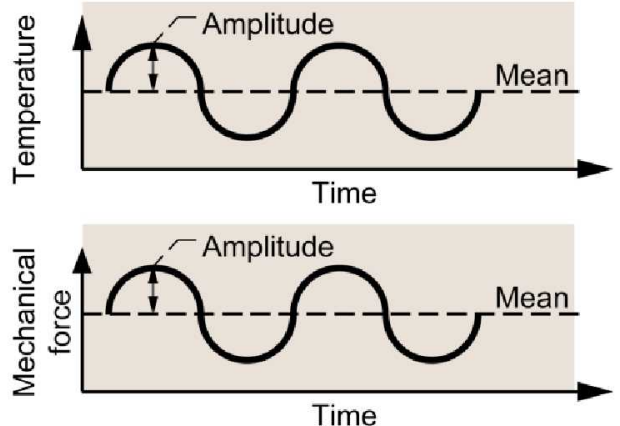

only the mechanical cyclic load (load cases 1 to 3 in Table 2). However, the category 2 load cases are only for thermal cyclic loads (load cases 4 to 7 in Table 2). In the category 3 load cases, the mechanical cyclic loads are combined with the thermal cyclic loads of different amplitudes such as $0,15.6,23.9,37.8$, and $51.7^{\circ} \mathrm{C}$ (load cases 8 to 22 in Table 2). The purpose of having these categories is to illustrate the combined effect of thermal and mechanical cyclic loads on the fatigue life reliability.

In each load case simulation, deterministic sensitivity evaluation of the fatigue life to each random variable was performed using perturbation analysis. ${ }^{7}$ Perturbation analysis means evaluating the change in the responses if the value of a particular random variable is changed by a given magnitude of standard deviation of that variable. From each perturbation analysis, the fatigue life for each ply was computed based upon the first-ply failure criteria. The shortest life of a ply in the laminate was considered to be the life of a laminate for that perturbation. Perturbation analysis is performed to develop a response surface which is required for the probabilistic analysis. By using these perturbation analysis results and probability distributions of random variables, the reliability analysis was performed using the FPI method. The CDF's and sensitivity factors for the first three load cases are summarized in Fig. 3. It shows the CDF of fatigue life caused by mechanical cyclic loads only. The fatigue life in these three cases was primarily governed by failure in $90^{\circ}$ ply because the transverse tensile stress was greater than the corresponding strength. Thus, the life under uniaxial tensile cyclic loads of that laminate is governed by the transverse tension failure in $90^{\circ}$ plies. Figure 3 also shows that the fatigue life CDF shift to the left means that the life under mechanical cyclic loads drops rapidly as the amplitude of applied cyclic stress increases. At load ratios, $r$, equal to 60,70 , and 80 percent, the respective mean fatigue life, $\mu$, was computed to be 88,40 , and 16 percent of the "endurance limit, $\mathrm{N}_{\mathrm{mf} .}$ " The corresponding scatter, $\mathrm{p}$, with respect to mean value is $14.4,26$, and 32 percent. Also, the respective fatigue life for 0.999 reliability is $49,9.3$, and 0.6 percent of $\mathrm{N}_{\mathrm{mf}}$ as shown in Fig. 4 (S-N curve) and Table 2. Thus, the fatigue life drops rapidly and the $p$ increases. Since ply transverse tension is the governing failure mode, the fatigue life for 0.999 reliability is sensitive to the $\mathrm{S}_{\mathrm{mT}}$, ply thickness, $\mathrm{E}, \mathrm{E}_{\mathrm{fl} 11}, \mathrm{k}_{\mathrm{f}}$, and $\mathrm{k}$. Note that the magnitude of sensitivity for a particular random variable almost remains the same with respect to different values of $r$. This means that the scatter in these variables should be minimized or controlled in order to enhance the fatigue life reliability under mechanical loads.

Table 1: Uncertainties in the constituent properties.

[Scatter, 5 percent; nominal distribution.]

\begin{tabular}{lc}
\hline \multicolumn{1}{c}{ Property } & Mean \\
\hline \hline \multicolumn{1}{c}{ Fiber } & \\
\hline Normal modulus, $\mathrm{E}_{\mathrm{f} 11}, \mathrm{GPa}$ & 213.7 \\
\hline Normal modulus, $\mathrm{E}_{\mathrm{f} 22}, \mathrm{GPa}$ & 13.8 \\
\hline Poisson's ratio, $\mathrm{v}_{\mathrm{f} 12}$ & 0.20 \\
\hline Poisson's ratio, $\mathrm{v}_{\mathrm{f} 23}$ & 0.25 \\
\hline Shear modulus, $\mathrm{G}_{\mathrm{f1} 2}, \mathrm{GPa}$ & 13.8 \\
\hline Shear modulus, $\mathrm{G}_{\mathrm{f} 23}, \mathrm{GPa}$ & 6.9 \\
\hline Tensile strength, $\mathrm{S}_{\mathrm{ft}}, \mathrm{GPa}$ & 2.8 \\
\hline Compressive strength, $\mathrm{S}_{\mathrm{fC}}, \mathrm{GPa}$ & 2.8 \\
\hline \multicolumn{2}{c}{ Matrix } \\
\hline Normal modulus, $\mathrm{E}_{\mathrm{m}}, \mathrm{GPa}$ & 3.4 \\
\hline Poisson's ratio, $\mathrm{v}_{\mathrm{m} 12}$ & 0.35 \\
\hline Tensile strength, $\mathrm{S}_{\mathrm{mT}}, \mathrm{GPa}$ & 0.1 \\
\hline Compressive strength, $\mathrm{S}_{\mathrm{mC}}, \mathrm{GPa}$ & 0.24 \\
\hline Shear strength, $\mathrm{S}_{\mathrm{ms}}, \mathrm{GPa}$ & 0.09 \\
\hline \multicolumn{1}{c}{ Fabrication variables } \\
\hline Fiber volume ratio, $\mathrm{k}_{\mathrm{f}}$, percent \\
\hline Void volume ratio, $\mathrm{k}_{\mathrm{v}}$, percent \\
\hline Ply thickness, $\mathrm{t}_{1}, \mathrm{~mm}^{2}$ & 60 \\
\hline
\end{tabular}


Table 2: Computational load Cases and reliability-based fatigue life.

\begin{tabular}{|c|c|c|c|c|c|c|}
\hline Case & $\begin{array}{c}\text { Mechanical } \\
\text { cyclic load } \\
\text { ratio, } \\
\text { r }\end{array}$ & $\begin{array}{c}\text { Mean } \\
\text { temperature, } \\
{ }^{\circ} \mathrm{C}\end{array}$ & $\begin{array}{c}\text { Cyclic } \\
\text { temperature } \\
\text { amplitude, } \\
{ }^{\circ} \mathrm{C}\end{array}$ & $\begin{array}{l}\text { Mean fatigue } \\
\text { life } \times \mathrm{N}_{\mathrm{mf}}\end{array}$ & $\begin{array}{l}\text { Scatter, } \\
\text { percent }\end{array}$ & $\begin{array}{c}0.999 \\
\text { Reliability } \\
\text { life } \times \mathrm{N}_{\mathrm{mf}}\end{array}$ \\
\hline $\bar{~} \overline{11}$ & 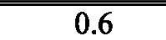 & 21.1 & 0.0 & 0.8792 & 14.40 & 0.4909 \\
\hline 2 & 0.7 & 21.1 & 0.0 & 0.3956 & 25.65 & 0.0934 \\
\hline 3 & 0.8 & 21.1 & 0.0 & 0.1609 & 32.3 & 0.0068 \\
\hline 4 & 0.0 & 65.6 & 15.6 & 0.9080 & 6.47 & 0.7318 \\
\hline 5 & 0.0 & 65.6 & 23.9 & 0.8623 & 6.91 & 0.6788 \\
\hline 6 & 0.0 & 65.6 & 37.8 & 0.7909 & 6.57 & 0.6287 \\
\hline 7 & 0.0 & 65.6 & 51.7 & 0.7254 & 6.73 & 0.5758 \\
\hline 8 & 0.6 & 65.6 & 0.0 & 0.9045 & 5.1 & 0.7616 \\
\hline 9 & 0.7 & 65.6 & 0.0 & 0.7785 & 5.42 & 0.6486 \\
\hline 10 & 0.8 & 65.6 & 0.0 & 0.6423 & 6.5 & 0.5118 \\
\hline 11 & 0.6 & 65.6 & 15.6 & 0.9278 & 5.6 & 0.7529 \\
\hline 12 & 0.7 & 65.6 & 15.6 & 0.8076 & 5.26 & 0.6744 \\
\hline 13 & 0.8 & 65.6 & 15.6 & 0.6736 & 4.03 & 0.5516 \\
\hline 14 & 0.6 & 65.6 & 23.9 & 0.8980 & 6.63 & 0.7126 \\
\hline 15 & 0.7 & 65.6 & 23.9 & 0.8231 & 5.51 & 0.6764 \\
\hline 16 & 0.8 & 65.6 & 23.9 & 0.6898 & 6.57 & 0.5433 \\
\hline 17 & 0.7 & 65.6 & 37.8 & 0.8186 & 5.45 & 0.6610 \\
\hline 18 & 0.8 & 65.6 & 37.8 & 0.6949 & 6.0 & 0.5590 \\
\hline 19 & 0.9 & 65.6 & 37.8 & 0.4009 & 44.0 & -0.1154 \\
\hline 20 & 0.7 & 65.6 & 51.7 & 0.7709 & 6.72 & 0.6143 \\
\hline 21 & 0.8 & 65.6 & 51.7 & 0.7047 & 6.15 & 0.5710 \\
\hline 22 & 0.9 & 65.6 & 51.7 & 0.3984 & 44.0 & -0.1159 \\
\hline
\end{tabular}
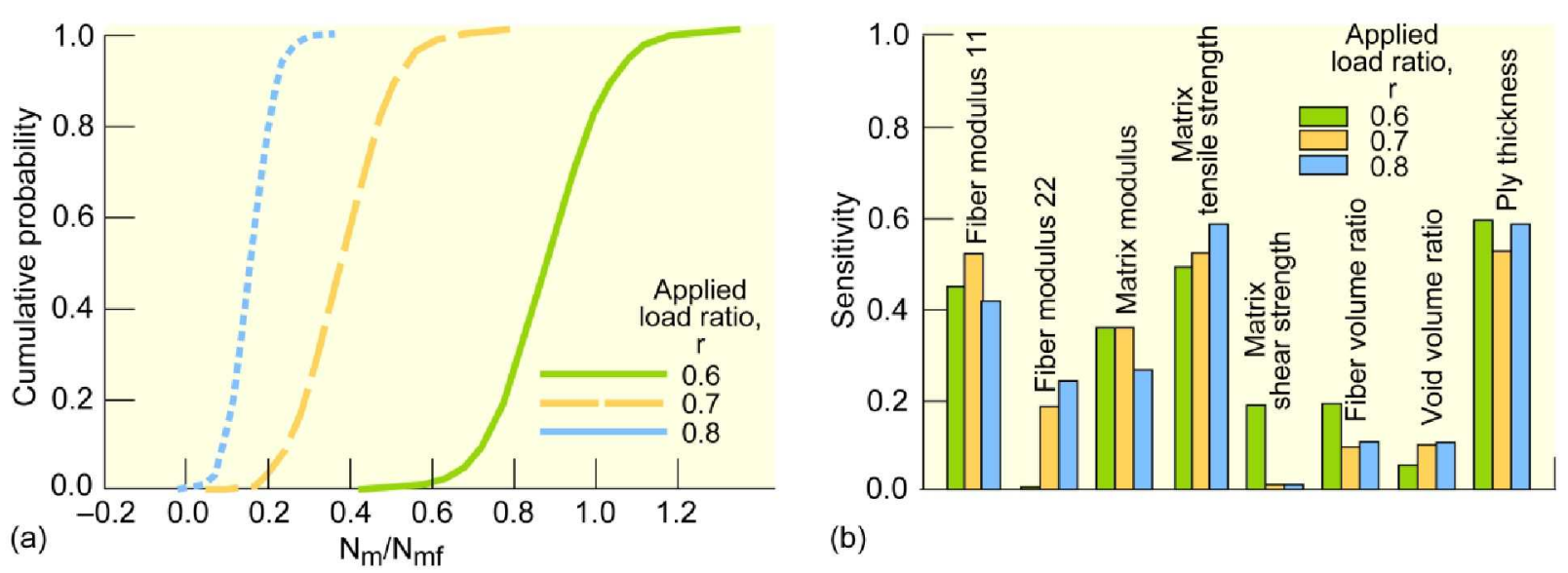

(b)

Figure 3. Cumulative distribution function for and sensitivity of fatigue life for 0.999 reliability of $(0 / \pm 45 / 90)$ s graphite/epoxy laminate. Ply thickness, $0.127 \mathrm{~mm}$ under mechanical cyclic load; mean mechanical load $=0.5 \times$ static strength. (a) Cumulative distribution function. (b) Sensitivity of fatigue life for 0.999 reliability.

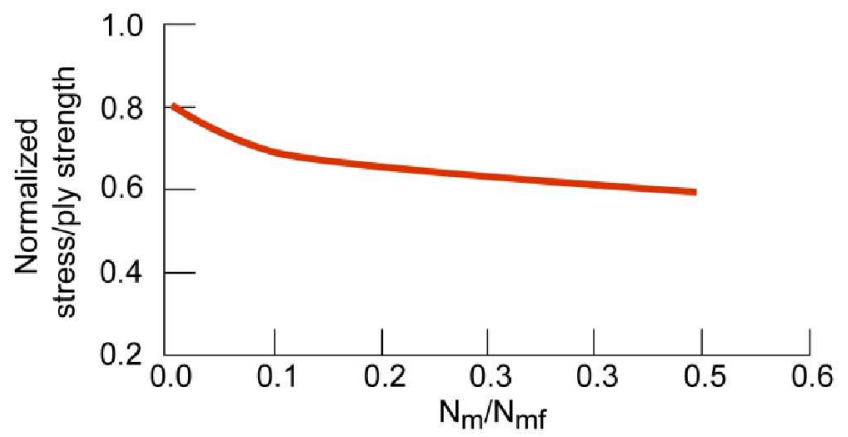

Figure 4. Fatigue life variation for 0.999 reliability of $(0 / \pm 45 / 90) \mathrm{s}$ graphite/epoxy laminate. Ply thickness, $0.127 \mathrm{~mm}$ under mechanical cyclic load. Mean mechanical load $=0.5 \times$ static strength. 

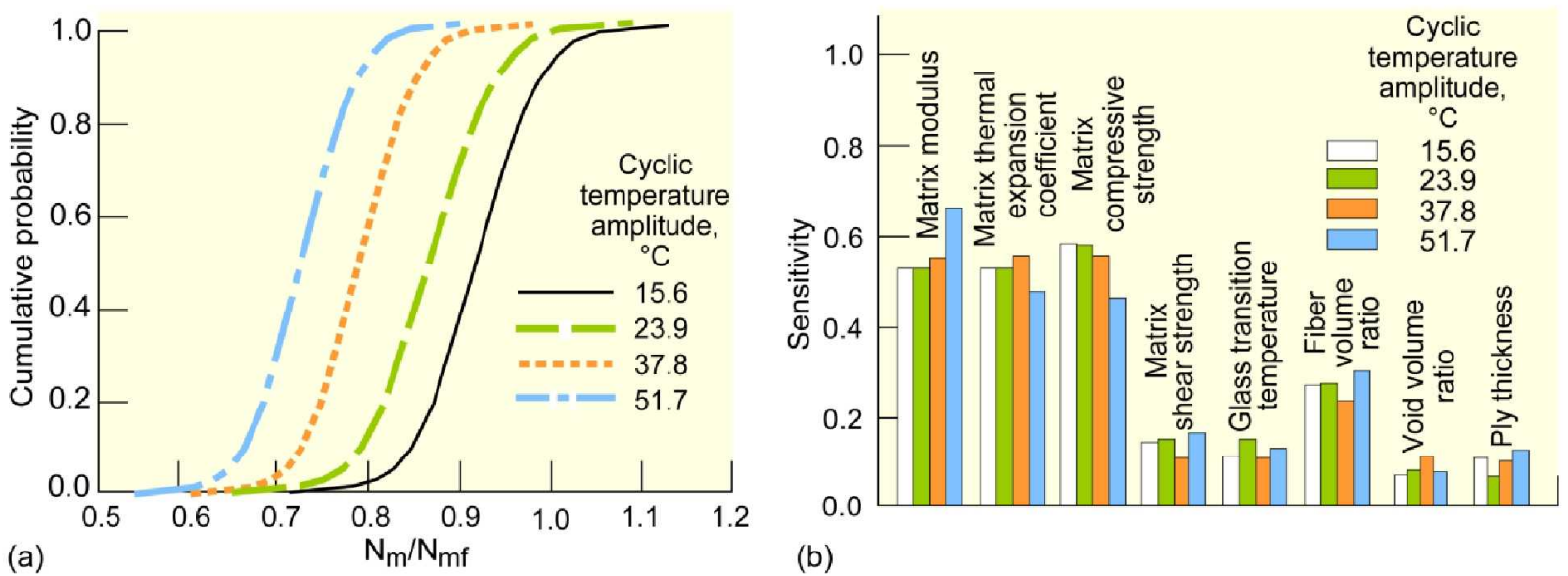

Figure 5. Cumulative distribution function for and sensitivity of fatigue life for 0.999 reliability of $(0 / \pm 45 / 90)$ s graphite/epoxy laminate. Ply thickness, $0.127 \mathrm{~mm}$ under thermal cyclic load; mean mechanical load $=0.5 \times$ static strength. (a) Cumulative distribution function. (b) Sensitivity of fatigue life for 0.999 reliability.

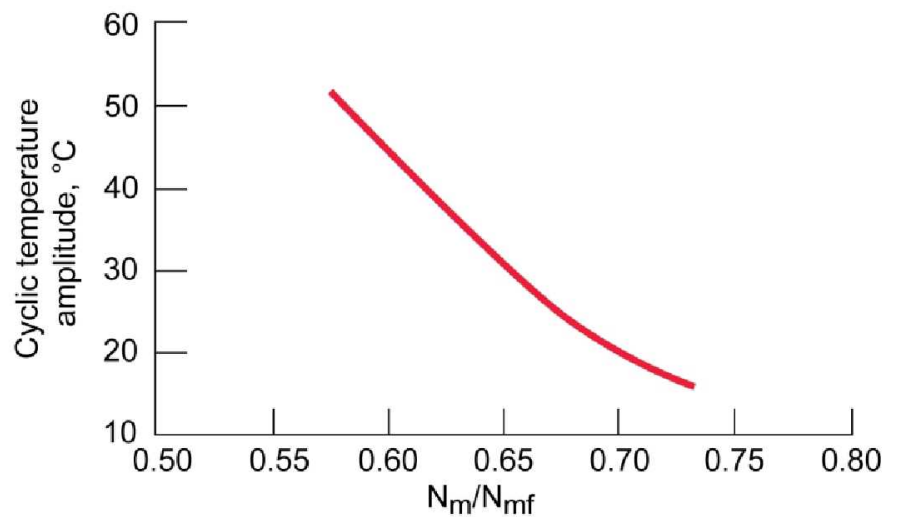

Figure 6. Fatigue life variation for 0.999 reliability of $(0 / \pm 45 / 90) \mathrm{s}$ graphite/epoxy laminate. Ply thickness, $0.127 \mathrm{~mm}$ under thermal cyclic load. Mean mechanical load $=0.5 \times$ static strength.

Figure 5 depicts the CDF's and random variable sensitivity for the fatigue life caused by variation in the cyclic temperature amplitude (load cases 4 to 7 and Table 2). Fatigue life caused by thermal cyclic loads in the laminate under consideration is mainly governed by the transverse compression failure in $90^{\circ}$ and $45^{\circ}$ plies. It is seen from this figure that the fatigue life variation is not as severe due to variation in cyclic temperature amplitude as was the case for mechanical load amplitude. The computed mean fatigue life, $\mathrm{m}$, for temperature amplitudes of 15.6, 23.9, 37.8 , and $51.7^{\circ} \mathrm{C}$ is $91,86,79$, and 73 percent of $\mathrm{N}_{\mathrm{mf}}$, respectively, whereas the scatter, $p$, is $6.47,6.91,6.57$, and 6.73 percent, respectively. Also, the respective fatigue life for 0.999 reliability is $73,68,63$, and 58 percent (Fig. 6 and Table 2). Thermal loads induce compressive stresses in the transverse direction of both $45^{\circ}$ and $90^{\circ}$ plies. Since allowable ply compressive strength is higher than the tensile strength, a higher life is expected under thermal loads. Also, as seen from Fig. 5, E, $\alpha, \mathrm{S}_{\mathrm{mC}}, \mathrm{k}_{\mathrm{f}}, \mathrm{S}_{\mathrm{mS}}, \mathrm{T}_{\mathrm{gd}}$ ply thickness, and $\mathrm{k}$ govern the fatigue life for 0.999 reliability.

Again, the magnitude of sensitivity for different thermal cyclic load amplitudes does not change much. The sensitivity trend of fatigue life to $\mathrm{S}_{\mathrm{mC}}$ is downward with the increase in the thermal load amplitude which is indicative of other eminent failure modes at very high thermal amplitudes. It is interesting to note that the scatter, $p$, remains the same at all amplitude levels.

Figures 7 to 11 are CDF's and sensitivity factors for the fatigue life under combined thermo-mechanical loading with cyclic temperature amplitudes of $0,15.6,33.9,37.8$, and $51.7^{\circ} \mathrm{C}$, respectively. Figure 12 shows the fatigue life design curves for 0.999 reliability. The mean fatigue life, scatter, and the life for 0.999 reliability for these load cases are given in Table 2. It is seen from Figs. 7 and 8 that the fatigue life CDF shifts to the left in proportion to the applied load ratio, $r$, at low thermal amplitudes of up to $23.8^{\circ} \mathrm{C}$ which means that the probability distribution of fatigue life does not change much. This is due to the fact that the failure mode up to $23.9{ }^{\circ} \mathrm{C}$ cyclic amplitude remains the same. This results in linear variation of the mean, scatter, and 0.999 reliability value of fatigue life (fig. 12). The variables that control the fatigue life magnitude at 0.999 reliability are ply thickness, $S_{m C}, S_{m s}, E, \alpha, T_{g d}, k_{f}$, $\mathrm{k}$, and $\mathrm{S}_{\mathrm{mT}}$. Ply thickness is the important variable in these cases caused by the mechanical load effects. 

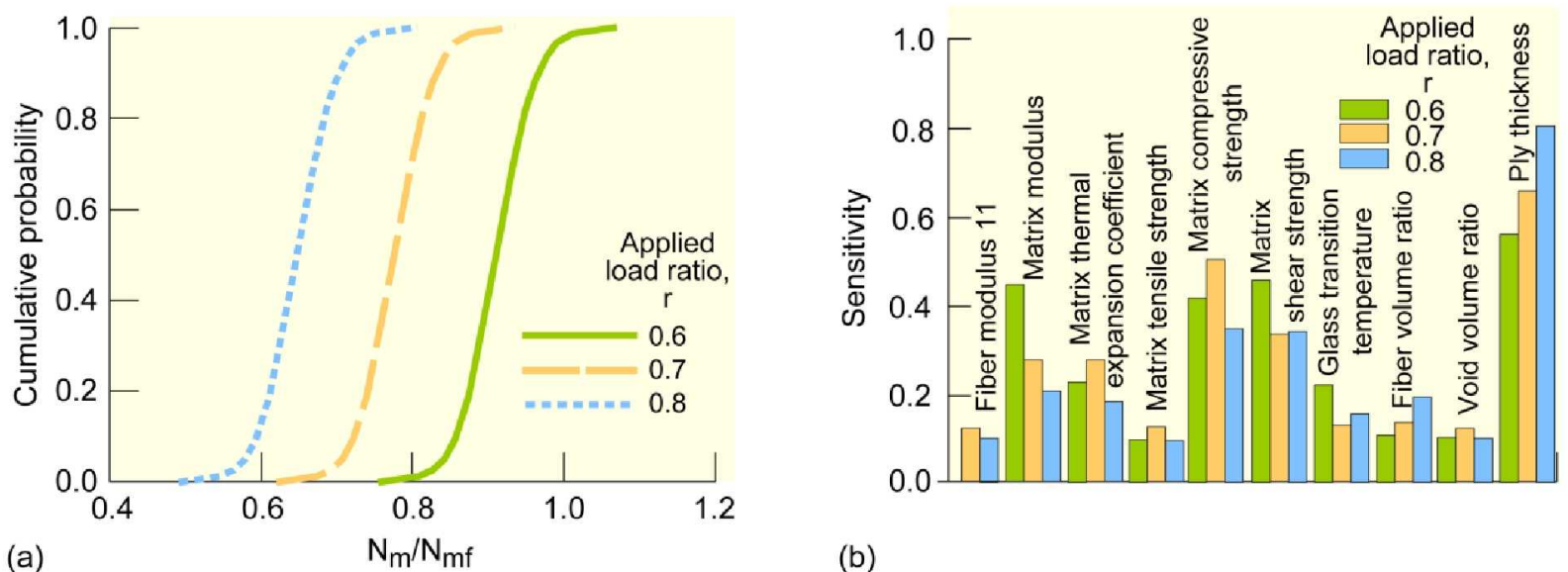

(b)

Figure 7. Cumulative distribution function for and sensitivity of fatigue life for 0.999 reliability of $(0 / \pm 45 / 90) \mathrm{s}$ graphite/epoxy laminate. Ply thickness, $0.127 \mathrm{~mm}$ under thermo-mechanical cyclic load; mean temperature, $65.6^{\circ} \mathrm{C}$; amplitude temperature, $0^{\circ} \mathrm{C}$. (a) Cumulative distribution function. (b) Sensitivity of fatigue life for 0.999 reliability.
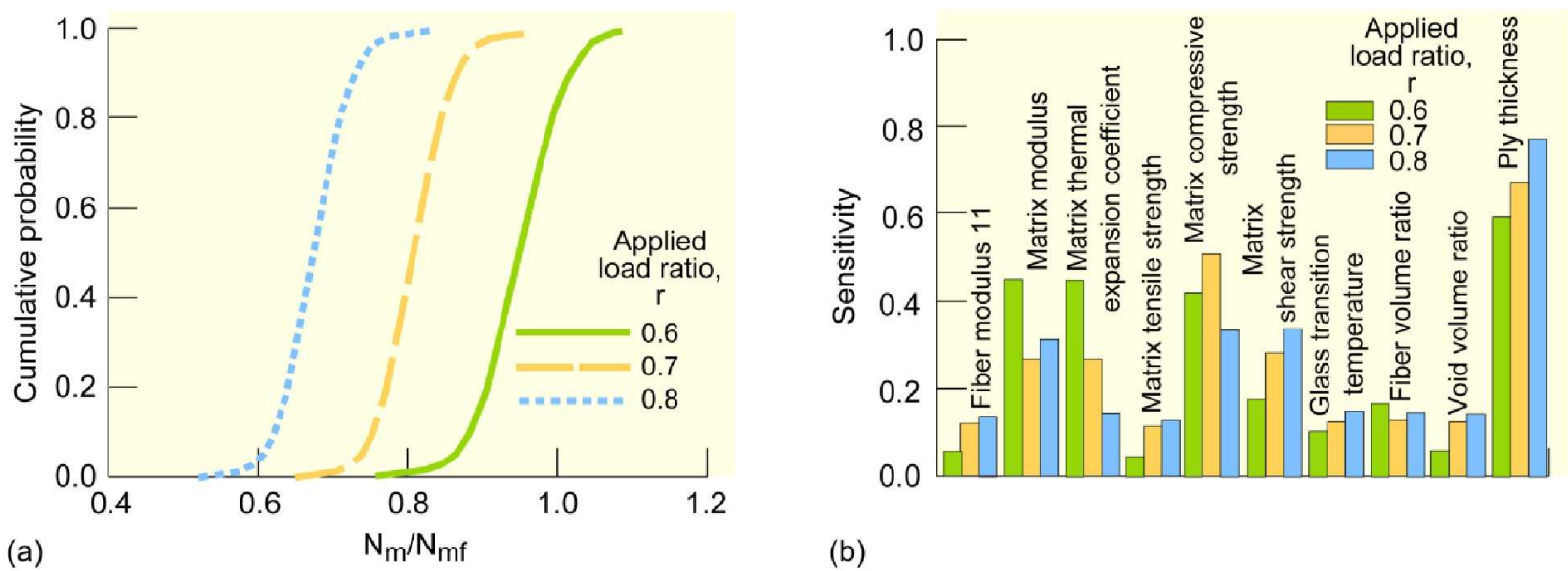

(b)

Figure 8. Cumulative distribution function for and sensitivity of fatigue life for 0.999 reliability of $(0 / \pm 45 / 90) \mathrm{s}$ graphite/epoxy laminate. Ply thickness, $0.127 \mathrm{~mm}$ under thermo-mechanical cyclic load; mean temperature, $65.6{ }^{\circ} \mathrm{C}$; amplitude temperature, $15.6^{\circ} \mathrm{C}$. (a) Cumulative distribution function. (b) Sensitivity of fatigue life for 0.999 reliability.
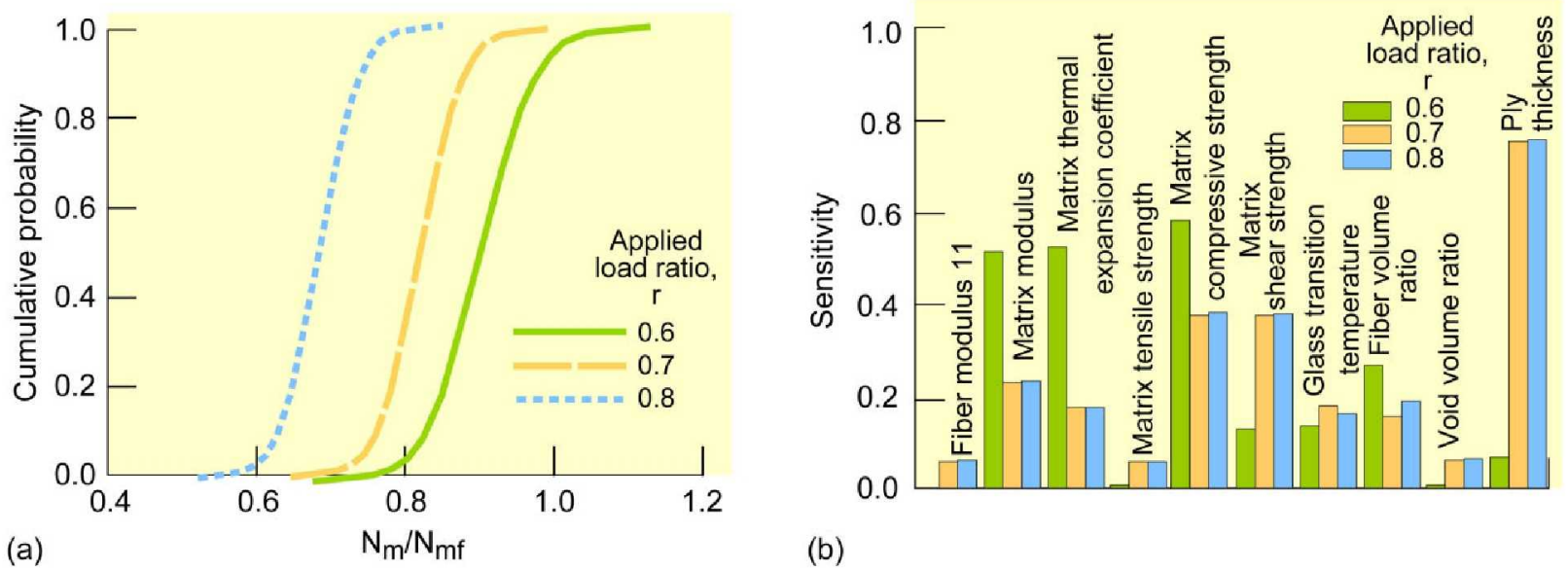

(b)

Figure 9. Cumulative distribution function for and sensitivity of fatigue life for 0.999 reliability of $(0 / \pm 45 / 90) s$ graphite/epoxy laminate. Ply thickness, $0.127 \mathrm{~mm}$ under thermo-mechanical cyclic load; mean temperature, $65.6{ }^{\circ} \mathrm{C}$; amplitude temperature, $23.9^{\circ} \mathrm{C}$. (a) Cumulative distribution function. (b) Sensitivity of fatigue life for 0.999 reliability. 

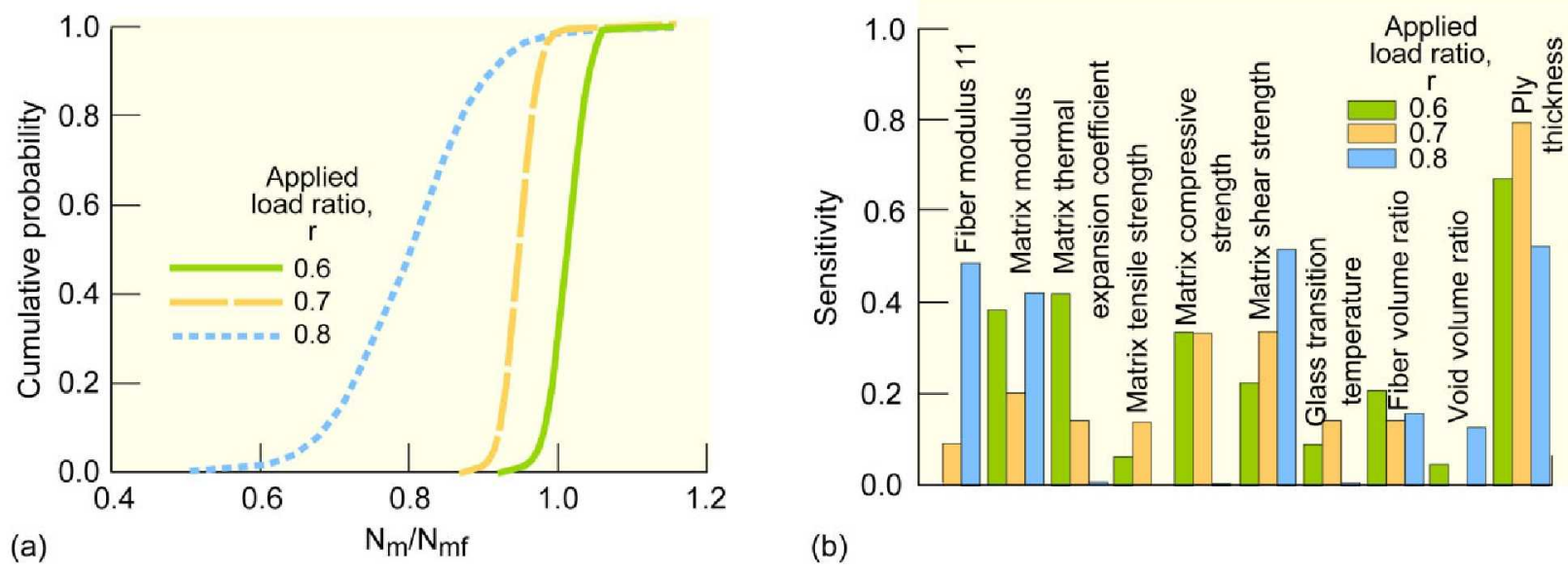

Figure 10. Cumulative distribution function for and sensitivity of fatigue life for 0.999 reliability of $(0 / \pm 45 / 90) \mathrm{s}$ graphite/epoxy laminate. Ply thickness, $0.127 \mathrm{~mm}$ under thermo-mechanical cyclic load; mean temperature, $65.6{ }^{\circ} \mathrm{C}$; amplitude temperature, $37.8^{\circ} \mathrm{C}$. (a) Cumulative distribution function. (b) Sensitivity of fatigue life for 0.999 reliability.
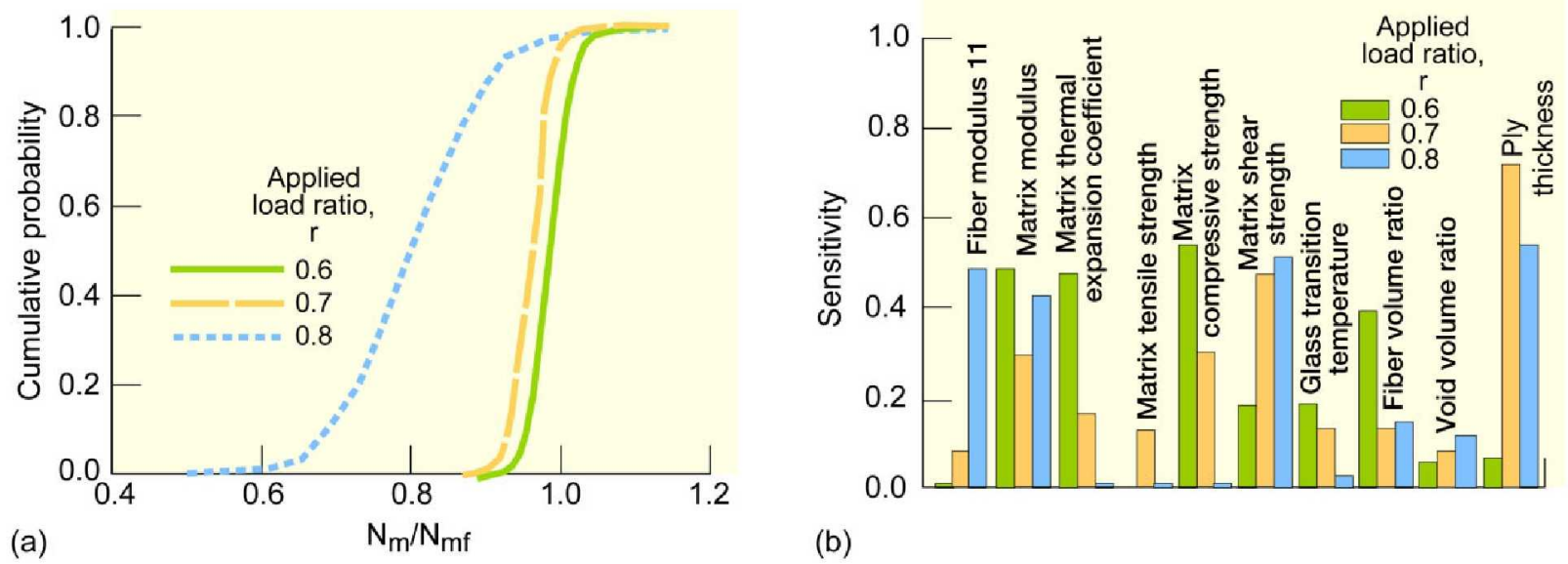

(b)

Figure 11. Cumulative distribution function for and sensitivity of fatigue life for 0.999 reliability of $(0 / \pm 45 / 90) \mathrm{s}$ graphite/epoxy laminate. Ply thickness, $0.127 \mathrm{~mm}$ under thermo-mechanical cyclic load; mean temperature, $65.6{ }^{\circ} \mathrm{C}$; amplitude temperature, $51.7^{\circ} \mathrm{C}$. (a) Cumulative distribution function. (b) Sensitivity of fatigue life for 0.999 reliability.

As the cyclic thermal amplitude increases, the shift in fatigue life CDF's is not in proportion to $\mathrm{r}$ as seen from Figs. 9 to 11. Thus, the trend in variation of $m, p$, and 0.999 reliability value of fatigue life gradually becomes nonlinear implying that the nature of probability distribution of fatigue life is not same at all load ratios. For amplitudes of 37.8 and $51.7^{\circ} \mathrm{C}$ it becomes highly nonlinear (refer to Fig. 12 and Table 2). This is due to the fact that, at low-temperature amplitudes, the failure is mostly governed by the longitudinal compressive strength in a $90^{\circ}$ ply whereas, at higher thermal amplitudes and low-load ratio, the governing failure mode shifts from $90^{\circ}$ ply to $45^{\circ}$ ply with compressive strength in the transverse direction being the limiting one. Also, at high-load ratio and hightemperature amplitudes, the failure mode is controlled by the shear strength in a $45^{\circ}$ ply. Thus, when the shear mode failure controls, the drop in fatigue life is also steep and the scatter in fatigue life increases dramatically.

As evidenced by sensitivity factors depicted in Figs. 9 to 11 , the fatigue life at 0.999 reliability at low-load ratio is dominated by $S_{m C}, E, \alpha, k_{f}$, and $S_{m s}$. However, at higher load ratios and thermal amplitudes, the fatigue life sensitivity to $S_{m S}, E_{f 11}$, and ply thickness increases whereas the others' effect decreases. Thus, it is seen that the nature of failure mode governs the reliability and corresponding variables become sensitive to the life. Also, it is observed that the shear failure mode causes a large scatter in the fatigue life as well as reduction in the life for 0.999 reliability. It can be seen from Fig. 12 that for the laminate under consideration, the 0.999 reliability cannot be achieved for load ratio, r, of 0.9 and thermal amplitudes of 37.8 and $51.7^{\circ} \mathrm{C}$. At this magnitude of reliability the fatigue life is negative in Fig. 12, meaning the laminate has already failed at this reliability. 


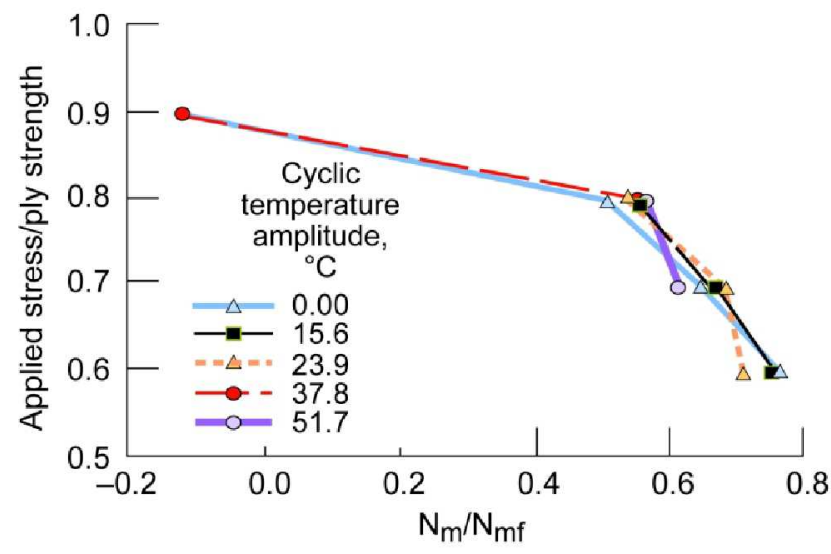

Figure 12. Fatigue life variation for 0.999 reliability of $(0 / \pm 45 / 90) s$ graphite/epoxy laminate. Ply thickness, $0.127 \mathrm{~mm}$ under thermo-mechanical cyclic load; mean temperature, $65.6^{\circ} \mathrm{C}$.

The information in Figs. 4, 6, and 12 can be used as a design aid to determine the component life for 0.999 reliability as well as to make decisions on its continuing use. Similar design curves can be developed readily for any polymer matrix composite with any laminate configuration and for any load conditions. It is also important to mention here that, when the failure mode changes for different perturbations under same load conditions, one should iterate the probabilistic analysis to ensure the convergence of reliability using advanced first-order mean value analysis given in Reference 7 . This is necessary because a small perturbation in the random variables could change the entire failure mechanism and the response surface becomes highly nonlinear which in turn affects the probability of failure. A reliability-based approach provides the level of reliability of a given design as well as identifies the controlling variables. Thus, it helps improve the manufacturing process, design experiments, and develop inspection guidelines.

\section{Conclusion}

A methodology to simulate the probabilistic fatigue life of polymer matrix composites under thermal and mechanical loads has been developed, implemented in the in-house computer code Integrated Composite Analyzer (ICAN), and demonstrated by the examples. The methodology incorporates the ICAN computer code, a generic time dependent multi-factor interaction equation model, and fast probability integration technique. Cumulative distribution functions of fatigue life cycles for a $(0 / \pm 45 / 90)_{s}$ graphite/epoxy laminate under uniaxial tensile cyclic loads and thermal cyclic loads were computed. Sensitivities of fatigue life to the random variables for 0.999 reliability were plotted. Fatigue life design curves for 0.999 reliability were generated for different combinations of thermal cyclic load amplitude and mechanical cyclic load. The importance of the failure mode on fatigue life reliability, scatter, and sensitivity were discussed. The fatigue life for $(0 / \pm 45 / 90)_{s}$ graphite/epoxy laminate under mechanical cyclic loads only was most sensitive to thickness and matrix tensile strength at 0.999 reliability since tension failure in $90^{\circ}$ ply controls the life. However, at low mechanical cyclic loads and low thermal cyclic amplitudes, the matrix compressive strength, matrix modulus, thermal expansion coefficient, and ply thickness were most sensitive to the fatigue life for 0.999 reliability since the transverse compression failure in $45^{\circ}$ and $90^{\circ}$ plies controls the life. Also, at high mechanical-cyclic loads and high thermal-cyclic amplitudes, shear failure in $45^{\circ}$ ply controlled the life. Therefore, at these load magnitudes, the fatigue life at 0.999 reliability was more sensitive to the shear strength of matrix, longitudinal fiber modulus, matrix modulus, and ply thickness. The reliability-based fatigue curves are useful in determining the allowable fatigue load on the structure or assessing the life of a given component. Sensitivity information provides guidelines to the designer to improve the reliability of the structure's fatigue life.

\section{References}

${ }^{1}$ Integrated Probabilistic Assessment of Composite Structures (IPACS) User's Manual. Ver. 1.0, NASA Contract No. NAS3-25266, Task Order No. 5209-02, Dec. 1991.

${ }^{2}$ Murthy, P.L.N.; and Chamis, C.C.: Integrated Composite Analyzer (ICAN): Users and Programmers Manual, NASA TP_ 2515, March 1986

${ }^{3}$ Boyce, L.; and Chamis, C.C.: Probabilistic Constitutive Relationships for Cyclic Material Strength Models. Proceedings of the 29th AIAA Structures, Structural Dynamics, and Materials Conference,pt. 3, J. Propul. P., 1988, pp. 1299-1306.

[4] Wu, Y.T.: Demonstration of a New Fast Probability Integration Method for Reliability Analysis. Advances in 
Aerospace Structural Analysis, O.H. Burnside and C.H. Parr, ed., ASME, New York,pp. 63-73, 1985.

5.Shah, A.R.; Singhal, S.N.; Murthy, P.L.N.; and Chamis, C.C.: Probabilistic Simulation of Long Term Behavior in Polymer Matrix Composites. Proceedings of the 35th AIAA/ASME/AHS/ASCE Structures, Structural Dynamics, and Materials Conference, April 1994.

${ }^{6 .}$ Shah, A.R; and Chamis, C.C.: Cyclic Load Effects on Long Term Behavior of Polymer Matrix Composites. Proceedings of the 40th International SAMPE Symposium and Exhibition, May 1995.

7. Probabilistic Structural Analysis Methods (PSAM) for Select Space Propulsion System Components User's Manual, South West Research Institute, NASA Contract NAS3-29389, Nov. 1989. 